\title{
GAMES PEOPLE PLAY: And How to Change Them....
}

\section{Mark Young}

\begin{abstract}
"Games" can be very widely defined, and we engage in them all. For this paper, I will be considering at least four kinds of games: first, the purely delightful children's (and adult) games, from board games to video games to competitive sports, that we play for pleasure. Second, the emotional games in the sense of Eric Berne (see below), i.e. the far less pleasurable psychological patterns that we seem to create and follow in our interactions with others, especially in situations of stress. Third, closely related to this, the games described and prescribed by game theory to analyse human behaviour in conflict. And finally, my own more playful exploration of the games of negotiation and the effect these have on negotiation process and results.
\end{abstract}

\section{Keywords}

Game, negotiations process, family, game archetypes

The urge to play is at least as strong as the urge to fight. A range of play theorists has made this point convincingly, starting with Huizinga (1949), but also Suits (1978), Carse (1986), and finally Kane (2004).

Certainly the history of mankind documents our deep-seated thirst for conflict, from divorces to wars, deep in every culture, and with devastating results. But we also have another need, one that is manifested in the delighted shouts emanating from a playground, the hushed concentration of a really good theater performance or the collective thrill of a convincing soccer goal shot in a packed stadium.

People deeply want to play. And exploring that urge can provide insights into human behaviour. But which really is stronger, the need to play or the need to fight, and can these two fundamental human urges be linked?

Eric Berne, in his seminal 1964 book 'Games People Play', was perhaps the first to seriously experiment with the idea of modelling human conflict as games. Under his interpretation, "games" are not so much playful activities as psychological interactions between people that can be troubled or effective, confused or insightful. Nevertheless, Berne identified patterns of conflict behaviour that yielded major insights into how to perhaps break those patterns and transcend conflict.

In ever more sophisticated work since then, first game theorists and now also conflict resolution 
practitioners have learned much about the power of game simulation to analyse conflict and also advise on its resolution and transformation. Along the way, the definition of "games" was transformed, from the psychological archetypes of Berne to more abstract patterns of conflict of classic game theory.

Building on more recent work by Rappaport (1967), and Halevy (2011), who isolated four particular archetypes of Conflict as Games, this short study explores the possible relationships between them. Following Halevy, we can consider the four games of Prisoner's Dilemma, Assurance, Maximizing Differences and Chicken, and in particular just what we can do once we realize we are in one of them. Questions to be addressed, include: Is there a way out? Is it possible to change the game? What can we do about it? Must we proceed to a fixed equilibrium? How do we "break out of the box" of predetermined payouts? How do we first come to recognize the game we are in, then understand the rules of that game and finally work proactively to change those rules or even transform the game into a different interaction entirely? In the short-run, this is first about changing the numbers in the boxes (altering payouts) but in the longer-term it is about changing perceptions, negotiating rules and building trust. How do we convince our partners to follow us to a new and more productive form of play together?

This is perhaps a new interpretation of what it means to be in a "game". For in my view, games are not just preset psychological patterns (Berne 1964) or even archetypes of conflict (Rappaport 1970 and Halevy, 2011). Rather, especially in the context of negotiation, they involve play and should be openended and never deterministic. We decide what games to play and, together, we write the rules and create the outcomes. We are not 'Prisoners' of our games but rather their authors. And we willingly engage in this kind of game.

The question for me, however, is by what methods do we strategically change the (dyadic) game we are playing in a given negotiation and swap it for another? I see potential for doing this either by intervening to alter the specific payouts of each game or by actively reframing perceptions on both sides of the table. For we can decide what game we choose to play, and so can our partner.

In that quest, perhaps we will discover newer archetypes of conflict. And perhaps one day we can leave the 2x2 matrix (see illustrations below) behind.

\section{FOUR GAME ARCHETYPES}

Nir Halevy (2011, et al.), building on the substantial literature on mental models and games in negotiation, has identified four principal conflict game archetypes, which, as he tells us, empirical testing has distilled from 576 theoretical possibilities. These are, in brief:

1. The Prisoner's Dilemma. Perhaps the best known model of a game, posits that two conflict parties, without communication, will both choose to defect (confess) rather than cooperate (each remaining silent), and thus end the game in a suboptimal equilibrium. In the parlance of the Prisoner's, both confess and both go to jail. 


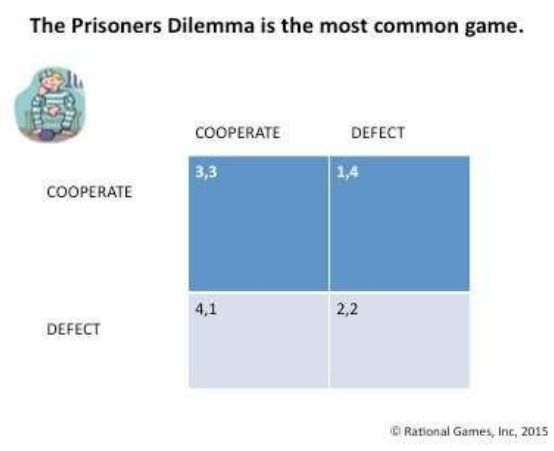

In a Prisoner's Dilemma the rational solution is always to defect, regardless of what the other side does: the potential for gain is thus maximized and the risk of loss minimized. If both do this, however, the total net utility of the equilibrium, Defect/Defect, translates into a Lose/Lose result for both.

Examples of Prisoner's Dilemmas are any kind of public choice problem or situations in which competitive dynamics cause parties to battle each other to a resolution in which both are worse off.

Individual rationality leads to a bad result. And the key driver that leads both to defect in this way is greed: the temptation of gaining more at the other's expense, as far as one can safely get away with it.

2 Assurance. Under the second archetype, assurance, players are propelled towards their desired payoffs not so much by greed as by first tenuous and then more robust trust. Each assumes the other will cooperate, and, when they do so, reciprocates in kind. Defections are usually matched by defections, but both sides are keen to get back to cooperation as soon as possible. And so the players come to establish a positive cycle of cooperation and also break negative cycles of defection. Given adequate communication, both players will realize this and gravitate towards a natural equilibrium of mutual cooperation. The result is Win/Win and the driver is reciprocation.

This is of course the fundamental game dynamic in any marriage, but also business partnership.

The Assurance Game is all about reciprocal trust.

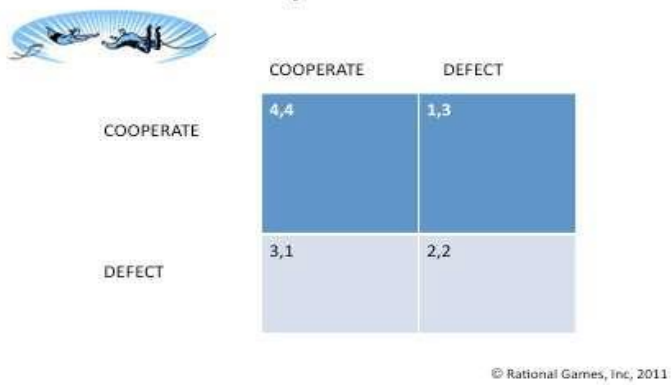


3. Maximizing Differences. In this game, the dynamic is different yet again. Here also, cooperation is theoretically always the best strategy, but it needs to be established through "training" the other side. While one might well defect, it would be only to punish the opponent while at the same time reducing ones' own payoff. While some game theorists call this dynamic "trivial" because it lacks competitive incentive, it does mirror the dynamics of many actual negotiations. The driver here is opportunity for mutual gains if the partner can be induced to go along.

An example might be any situation of unequal power, where one side is in a position to "train" behavior in the other, i.e. the context of management and leadership.

Again, the equilibrium is cooperation, but it is less robust than under Assurance and requires constant vigilance.

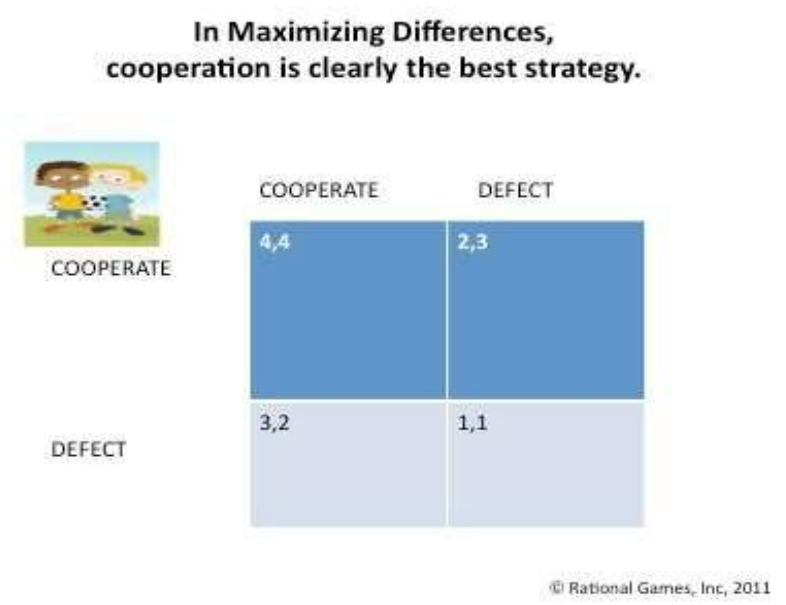

4. Chicken. The fourth and most dangerous game is chicken. Here there is no real payoff under any scenario other than winning at the other's expense. Just as in the classic teenager game of two cars racing towards each other on the highway, defection is strength and cooperation is weakness. There can only be one winner or two catastrophic losers. While a last minute swerve is certainly preferable to total destruction, it is a weak outcome compared to the infinitely preferable unilateralvictory.

Many political negotiations are of this ilk, especially recent budget negotiations in the United States that led to an agreement in which each side gained some of what it sought while relinquishing other goals.

Because each side assumes that the other will choose the fairly small loss of "swerving" away when comparing it to the devastation of collision, the risk is heightened that both will stay on course. In any case, the driver is fear of total destruction. 
In Chicken, the one who blinks first loses.

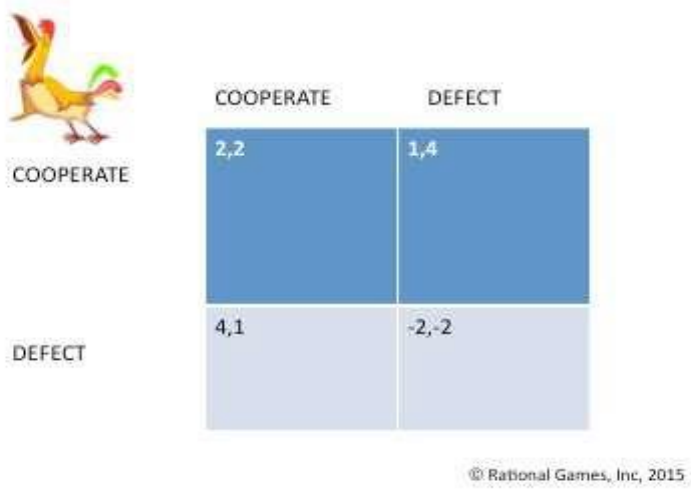

In summary, the four game archetypes differ from each other in two fundamental respects (see the graphic below). First, the driving force to either compete or cooperate is systematically programmed into the game, by the payouts that are there before the game starts. The drivers of trust-reciprocity, opportunity and fear-are thus not only understandable, but unavoidable. Rational players will and must be guided by them.

Second, the shared assumption as to whether the negotiation pie is fixed or expandable determines the parameters of the play. In Chicken, there is nothing to gain from cooperation or concession as each player's gain is automatically "financed" by a loss to the other side. The other three models allow for more creative bargaining as cooperation can create mutual gains.

\section{Four Archetypal Games of Conflict}

\begin{tabular}{|l|l|l|}
\hline & Assumption about the Pie & DRIVING FOREE \\
\hline PRISONERS 'DILEMMA & Expandable & $\begin{array}{l}\text { Trust, cooperation OR } \\
\text { greed }\end{array}$ \\
\hline ASSURANCE & Expandable & $\begin{array}{l}\text { Cooperation, but only if it } \\
\text { is mutual }\end{array}$ \\
\hline CHICKEN & Fixed & $\begin{array}{l}\text { Courage, boldness, } \\
\text { fortitude }\end{array}$ \\
\hline MAXIMIZING DIFFERENCES & Expandable & Cooperation, coordination \\
\hline
\end{tabular}

\section{CHANGING THE GAME}

Having once recognized which game we are playing in a negotiation (in itself no small feat), we must then ponder what, if anything, to do about it. Rather than deterministically chasing payoffs as dictated by the particular predetermined game structure, how do we rise to the challenge of questioning 
the game itself? Just as importantly, how do we convince our play partner to join in that exercise?

Good negotiators not only decide what moves to make in a game, but they can also decide which game they choose to play - or indeed, whether to engage in a game at all. And they can invite their partner/opponent to ratify that choice, either consciously or intuitively.

It seems to me there are three fundamental ways to change the game:

1. Change the payoffs in the game (trust-building)

2. Change the players' perceptions of those payoffs (reframing) or

3. Change the parameters permanently (game transformation).

\section{Changing payoffs}

The game archetypes described above are defined largely by the payouts in the boxes. As those numbers change so that dominant strategies shift, the behaviour of the players moves them automatically into a new archetype. From Chicken, they may move to the Prisoner's Dilemma. From Maximizing Differences can come Assurance. But what enables this to happen?

The key here is trust-building. Payoffs change as the probability of their occurrence changes, and that is a direct result of the firmness of our conviction that the other party will not act to our detriment. If the risk of cooperation recedes, the reward of a greater payoff beckons. And so rational players will automatically choose to gain that payoff, thereby changing the game from within.

David McAdams, in his recent book Game Changer (2014) offers a useful description of just how trust-building can help to change payout especially the Prisoner's Dilemma game. He refers especially to:

Changing the timing of moves. Simple re-sequencing can have a profound effect on trust. First movers must always make assumptions about second movers, assumptions that are usually conservative and riskaverse. When it is no longer clear who goes first, these assumptions are called into question. Engineering an arrangement where moves are truly made in parallel or even where second movers become first movers can shake up the payout structure and enable cooperation, especially in the Prisoner's Dilemma game.

This is of course the principle behind Escrow accounts, and also most online asset-sharing sites. But it is also used in financial auctions. The sequence of bids received, payments made or services rendered can have a profound effect on overall results. As trust increases, so does the value created for all.

Closely related to this is the technique of precommitment. By "burning my boats behind me" before we even start, I can convince my partner that I no longer have any other option than to do as I say: it has been publicly announced, there are witnesses or I would suffer severe consequences for defection. This technique can be used to make threats credible but also, in a more benign way, to reduce the risk of defection and make cooperation possible. 
Here again, we are simply reducing the uncertainty of promise fulfilment. If I am reasonably sure you will do as you say, I am more likely to risk cooperation.

Tit for Tat discipline. Entire books and studies have been written about the Tit for Tat strategy: quick to trust, quick to punish, quick to forgive. Suffice it to say we can effectively train our opponent not to defect: first issue an immediate offer of cooperation, then inflict swift retribution for defections, followed by renewed offers of cooperation. In this way, a Prisoner's Dilemma game can be stabilized and "solved" through the creation of more lasting patterns of cooperation. In the end, players can sometimes even transform the game to Assurance or at least Maximizing Differences. The game changes slowly over time, from within, assuming repeated interactions, and eventually "takes off" as the trust behaviour becomes innate and the vision of what is possible increases exponentially.

Note that this strategy is fairly ineffective with Chicken, given the lack of repeated moves. It is the relationship dimension that allows the trust to build. But this relationship dimension is almost always present in most business negotiations, which are embedded in a web of relationships. You never know whom you will meet again and where - or their friends and online connections.

- Third party intervention. Finally, especially the Prisoner's Dilemma game can be easily transformed through the presence of a third party. For problems of externalities, this could be a regulator and in situations of conflict a mediator or arbitrator. In either case, payouts of cooperative moves are enhanced by the value added or discipline imposed. We are still within the Prisoner's Dilemma game, but more likely to get to a result that truly creates added value for both parties.

Third parties, especially those with institutional power such as judicial, regulatory or moral authority can propose new ideas, enforce new rules of engagement or introduce new incentives or disincentives to action, thereby changing payouts within the game.

This kind of regulated intervention is at the heart of public choice problems as well as any kind of mediated solution.

Changing frames. The second way to significantly change a game is the realization that the game is not only about payoffs, but also about player perception of those payoffs. And changing those perceptions opens a range of possibilities for game transformation.

Even if the numbers do not change objectively, it is sufficient if the player perception and valuation of those numbers is questioned and affected.

Organizational psychologists—especially Tversky and Kahnemann (2000), but also Druckman, (2000), Clark (2009) and Plous (1993) —have written in recent years about the power of psychological framing, recognizing that we perceive reality selectively, and always through a lens colored by our beliefs and values. Understanding not only our own frames but also those of our opponents can help greatly to change negotiation behavior.

A copyright obligation could, for example, also be seen as a licensing opportunity. The cost of a consulting service could seem exorbitant as a lump sum but reasonable when compared to the savings realized. And an open conflict between parties may also contain the opportunity to work together to 
satisfy our respective home fronts.

In this way, risks can be seen as opportunities. We can encourage the other side to look at the bigger or the smaller picture. We can spur creativity with new angles, new ways of seeing things. And the work of changing payoffs occurs in the players' heads, as they realize that they value things more or less than they thought. The actions follow naturally, and the game is transformed.

\section{Game transformation}

Finally, we must consider the most radical possibility: consciously exiting the interaction and negotiating the game itself. By stopping the game in mid-play (Bill Ury calls this "going to the balcony" (Getting Past No,) and instead moving to a level of "meta- negotiation" we can identify and articulate what we see happening in the game, and question whether both sides truly want to continue the interaction as it stands. The game itself becomes the subject of ournegotiation.

The entry into this sort of discussion, as good mediators know, is serious wrestling with the rules of engagement. What are the current rules of our game and how should they be changed if we decide to move to another? Can we agree on this procedurally before we dive back into substance? A commitment to rules and values is an excellent foundation for renewed engagement with sustained conflict.

\section{A PRACTICAL EXAMPLE: THE CASE OF CUBAN-AMERICAN RAPPROCHEMENT}

Even as I write this short thought piece, a rather extraordinary example of profound game change is unfolding in the political sphere. Recently, „wwo powerful negotiators moved from a deeply entrenched game of Chicken and made the first hesitant steps towards a new and far more promising interaction of Maximizing Differences or even Assurance. I am of course speaking of the truly historic und unexpected diplomatic opening between the USA and Cuba.

For decades, these two adversaries were locked in a classic Game of Chicken, which started literally at the brink of nuclear war, and then became hardened into a semi- permanent lose-lose state of animosity. For both parties, there was absolutely no benefit to cooperation and each was driven by the hope that somehow they could annihilate the other and prevail unilaterally. Mutually unblinking hostility and unbending refusal to change course cemented the game and precluded any hope of exit for either side.

Just what happened in recent months to galvanize the change is cause for much speculation, and certainly the dynamics of the current negotiation go well beyond any adequate coverage in a short paper. But some of the rather intriguing contours of the emerging game change are now becoming clear, and offer an instructive example of how deep game transformation works in practice.

The initial icebreaker was, endearingly, quite personal. Senator Jeff Flake, one of the staunchest anticommunists in the US Congress, on a February 2013 peacemaking trip to Havana, was approached by a Cuban woman requesting the release of frozen sperm from her husband, imprisoned in the US on espionage charges, to fulfil their dream of a child. Senator Flake had the foresight to make discreet 
enquiries, linking these immediately to the long-sought release of Alan Gross, an American "spy" imprisoned in Cuba, and in failing health. The combined personal urgency of a newborn baby and a dire medical emergency merged to create a powerful emotional appeal to decision-makers on both sides.

To follow the taxonomy of this paper, both Obama and Castro then continued with careful new moves within the Game of Chicken. Starting with the timing of little steps, each volunteered a cooperative move as a response to a trust signal from the other: very limited relaxation of travel restrictions by the US government led to the release of lower- level political prisoners on the Cuban side. The spy swap of Alan Gross for the Cuban Five held in the US was agreed. A remarkably vitriol-free public speech by Castro enabled the historic handshakes in Soweto and then in CostaRica.

Pre-commitment also played a major role. Public advance announcements by the US that Cuba was to be removed from the terrorist list emboldened the Cubans to further liberalize the economy in increasingly important ways. Of course, both parties ensured they had a back door: Obama made it clear that larger steps forward would need the approval of a sceptical US Congress, and the Cubans reminded all who wanted to hear that their system allows for liberalization measures to be unilaterally repealed without notice. But the movement had started, and the payouts in the boxes began tochange.

Crucially in this negotiation, third parties played a decisive role. By embedding some of the theatre of reconciliation in the OAS Summit, the two warriors engaged witnesses who validated the truce. Even more importantly, back channel negotiations in Canada and through the Vatican were immensely helpful. The Pope, a revered figure in Cuba, used his moral authority to engage both the deeply Catholic Cubans as well as a US President much in need of a moral imprimatur to convince a hostile but fairly religious Congress. The extent of this involvement will certainly be the subject of future exposition of these remarkable first steps.

And so, slowly, the prospect of a more lasting relationship emerged. As the game looked to possibly become repeated, Tit for Tat began to take effect, and both parties learned that they could discipline the other to cooperate with minimal risk to themselves. The Game was still Chicken, but it was already much less dangerous, more humane and more promising for each.

But these players have also already begun to question the game itself. Realizing that it is perceptions of payouts that count, both have become aware of the potential that exists for the relationship if it can be successfully reframed. What exactly do US-Cuban relations represent? What is the larger prism through which each party sees the other?

For decades the two had engaged in a Mini-Cold War, with Cuba playing the role of docile standin for its patron the USSR, and the Americans viewing this as one more particularly dangerous front in the general war on Communism. All the rules of nuclear war applied here as well, and Mutually Assured Destruction seemed an acceptable strategy.

As the vitriol began to spread to Venezuela, both began to realize the very real damage their animosity was causing to the neighbourhood at large. Cuba and the USA are, after all, geographic neighbours, both members of the Western Hemisphere with a natural interest in good relations. And they began to realize their shared interest in reversing that. 
It also became clear that this relationship was not only political but extended to other shared interests as well. First initial steps were taken in joint efforts in disaster relief, particularly in combating Ebola. Economics were a key concern of both sides: Cuba is not a large market for the US, but it is an important way into the larger Latin American sphere. Certainly there is potential for mutually beneficial business arrangements, if only the political hurdles can be overcome.

At the time of this writing, the parties seem to be moving towards full game transformation. It seems clear that, once serious negotiations start with the aim of eventual full diplomatic relations, the focus will be on creating a lasting and sustainable Game of Assurance. From an initial discussion of new ground rules, I would expect these smart negotiators to create rituals and institutions that consolidate the initial gains and stabilize the newly-won mutual rewards, vastly increasing the chances for a mutually positive result. If they pull it off, it will be a truly historic negotiation success, one that would indeed validate the Nobel Peace Prize won by Mr. Obama in 2009.

\section{NEXT STEPS, AND LESSONS LEARNED}

What lessons can be taken from all this for negotiation analysts and especially for practitioners? Can these insights grounded in game theory be useful even in more modest conflict situations, ones that do not come from international diplomacy and where the stakes are not quite as high? While there is still much thinking to be done on this front, we can certainly draw a few useful precepts from this analysis, recommendations that could well change the dynamic of some of our all too automatic gameplaying:

1. Understand the game you are in. David McAdams calls this "game awareness" and writes persuasively of its power in his book Game Changer (2014). The simple realization of which game is being played is first and a major step in the direction of positive change. For we always have a choice, not only about the moves we make but about the games we choose to engage in. So take a break, step back and see if you can accurately assess just where you and your negotiation partner are headed. Are you happy with that potential result?

2. Be bold enough to see the potential for a new game. The technique of "framing" described above can be learned, and starts with each negotiator's own perception of the game. Once you understand the parameters of your current interaction, see if you can imagine something totally different. Think bigger. Question assumptions. Sketch a path-breaking vision of a new and alternative game, and think how you might persuade your partner to engage in it.

1. Start with the little things. Entrenched games are difficult to change and unexpected signals can be dangerous as well as liberating. Do not seek to resolve major deadlocks on key issues overnight. Smaller "throwaway" items are much better suited to experimentation and signalling. Build momentum slowly. And then encourage the other side to reciprocate in kind. 
Trust but verify. This maxim was helpful long before it was spoken by Ronald Reagan in connection with ballistic missile negotiations with the Soviet Union. Realize that ANY loosening of an established game risks exploitation by the other side. Unilaterally repeated cooperative moves can lead to loss of respect, and any agreement reached in a confrontational game must be tested and verified before proceeding to the next issue. Trust is essential, but naiveté is expensive. You cannot change the game by yourself.

3. Let the game unfold. Game theory assumes a closed system, one in which payouts in a $2 \times 2$ matrix fully determine player moves. But if we succeed in changing the game, perhaps we can explode even that assumption. In a truly open interaction, new possibilities emerge, new moves materialize and new value is imagined and captured. Eventually, perhaps we can leave the world of matrices behind.

Negotiation is indeed a game, one of the most central ones that we play in life. But, to return to Eric Berne, it needs to incorporate the Parent and the Adult as well as the Child. Enjoy the play, with abandon. But always be conscious of which game has been selected, and remember that you can choose to change that. That is what enables unfettered but also productive strategic play. 


\section{REFERENCES}

Bazerman, M., Curhan, J., Moore, D., Valley, K. (2000) Negotiation, Annual Review of Psychology, 51, 279314.

Bornstein, G., Gilula, Z. (2003) "Between-Group Communication and Conflict Resolution in Assurance and Chicken Games", in Journal of Conflict Resolution, 47(3) 326-339.

Carse, James P., Finite and Infinite Games, 1986, New York, Ballantine Books.

Devetag, G., Warglien, M. (2008) Playing the Wrong Game: An Experimental Analysis of Relational Complexity and Strategic Misrepresentation, Games and Economic Behavior, 62 (2) 364-382.

Halevy, N., Chou, E., Murnighan, K. (2011) Games Groups Play: Mental Models in Intergroup Conflict and Negotiation, Negotiation Group Research, 14, 81-109.

Halevy, N., Chou, E., Murnighan,K. (2012) Mind Games: the Mental Representation of Conflict, Journal of Personality and Social Psychology, 102(1) 132-148. Huizinga, J. (1949) Homo Ludens, London, Routledge.

Kane, P. (2004) The Play Ethic: A Manifesto for a Different Way of Living. London, PAN Books,

McAdams, D. (2014) Game Changer: Game Theory and the Art of Transforming Strategic Situations, New York, W.W. Norton and Company.

Rapoport, A. (1967) Exploiter, Leader, Hero and Martyr: the Four Archetypes of the 2 x 2 Game, Behavioral Science, 12, 81-84.

Roberts, D. (2015) Spies, Artificial Insemination and the Pope: How Cuba came in from the cold, The Guardian, 26 April 2015.

Suits, B., (1978) The Grasshopper: Games, Life and Utopia, Toronto, Toronto Press.

The White House, Office of the Press Secretary (2014) Statement by the President on Cuba Policy Changes, December 17, 2014.

Van Boven, L., Thompson, L., (2003) A Look into the Mind of the Negotiator: Mental Models in Negotiation. Group Processes Intergroup Relations, 6, 387-404.

Mark Young is an independent consultant, trainer, writer and lecturer in the field of mediation and negotiation skills training and analysis; his company, Rational Games, Inc, (www.rationalgames.com) serves a variety of clients in the public and private sectors in the US, UK and Germany. Mark's business career has afforded him ample opportunities to do so, as he has served as a corporate lending officer at Chase Manhattan Bank, a strategic consultant at McKinsey \& Company, a partner at Price Waterhouse Corporate Finance and a trade negotiator in the US Department of Commerce.

Mark is also a social entrepreneur. His firm is registered as a non-profit in the US and Germany and makes small grants to organizations with innovative ideas for using games and play to resolve conflict. 